\title{
High tuberosity healing rate associated with better functional outcome following primary reverse shoulder arthroplasty for proximal humeral fractures with a $135^{\circ}$ prosthesis
}

\author{
Jonas Schmalzl ${ }^{1 *}$ D, Malik Jessen ${ }^{1,2}$, Nadine Sadler ${ }^{1}$, Lars-Johannes Lehmann ${ }^{1,2}$ and Christian Gerhardt ${ }^{1}$
}

\begin{abstract}
Background: Reverse shoulder arthroplasty (RSA) is a common treatment for proximal humeral fractures. (PHF) in the elderly. This study evaluates the functional outcome and the influence of. tuberosity healing (TH) following RSA with $135^{\circ}$ humeral inclination and a neutral glenosphere without lateralization for PHFs.

Methods: In this retrospective case series, all patients with an acute PHF treated with primary RSA with $135^{\circ}$ humeral inclination and a standard glenosphere without lateralization during a four-year period were followed up. Constant score (CS), patient satisfaction (subjective shoulder value (SSV)), TH and glenoid notching were analyzed.

Results: 38 patients with a mean age of $77 \pm 8$ years were available for follow-up at $34 \pm 5$ months. The mean adjusted CS was $61 \pm 9$ points. TH of the greater tuberosity (GT) was $82 \%$ and resulted in significantly improved abduction $\left(117^{\circ}\right.$ vs. $\left.81^{\circ} ; P<0.001\right)$, forward flexion (139 vs. $\left.99^{\circ} ; p<0.001\right)$, external rotation $\left(28^{\circ}\right.$ vs. $\left.10^{\circ} ; p=0.002\right)$, CS (65 vs. 41 points; $p<0.001$ ) and patient satisfaction (SSV 79\% vs. 48\%; $p<0.001$ ). TH of the LT was $87 \%$ without affecting internal rotation or overall outcome. The complication- and revision rate was 5\%; implant survival was $100 \%$. Scapular notching occurred in $3(8 \%)$ cases (all grade 1).

Conclusion: RSA with $135^{\circ}$ humeral inclination and a standard glenosphere for PHF leads to good functional outcome in combination with a high rate of $\mathrm{TH}$ and a low rate of scapular notching. The short-term revision rate is low and the results are predictable and continuous. TH is associated with improved ROM, patient satisfaction and functional outcome.
\end{abstract}

Keywords: Humeral inclination, 135, Tuberosity healing, Proximal humeral fracture, Reverse shoulder arthroplasty

\section{Introduction}

Proximal humeral fractures (PHF) account for $5 \%$ of all fractures [1, 2]. Avascular necrosis of the humeral head after trauma or after osteosynthetic treatment of PHF represents a major problem of joint-preserving therapy approaches [1, 3-5]. Especially in the elderly, the results after osteosynthesis might not be satisfactory and revision

\footnotetext{
* Correspondence: jonasschmalzl@gmx.de

${ }^{1}$ Department of Traumatology and Hand Surgery, St. Vincentius Clinic, Karlsruhe, Academic Teaching Hospital Albert-Ludwigs-University Freiburg, Suedendstraße 32, D-76137 Karlsruhe, Germany
}

Full list of author information is available at the end of the article rates up to $25 \%$ are reported [6]. Due to decreased bone quality, comminution and displacement as well as the aim to decrease revision surgery, arthroplasty is commonly used to treat PHF in elderly with a high risk for vascular compromise. However, functional outcome after hemiarthroplasty (HA) for acute PHF in patients older than 70 years have been disappointing and unpredictable [7-10]. This is mainly attributed to poor bone quality associated with low tuberosity healing $(\mathrm{TH})$, severe comorbidities and incompliance to the rehabilitation protocol [11]. After the development of reverse shoulder arthroplasty (RSA) by Paul Grammont [12] several studies have demonstrated

(c) The Author(s). 2020 Open Access This article is distributed under the terms of the Creative Commons Attribution 4.0 International License (http://creativecommons.org/licenses/by/4.0/), which permits unrestricted use, distribution, and reproduction in any medium, provided you give appropriate credit to the original author(s) and the source, provide a link to the Creative Commons license, and indicate if changes were made. The Creative Commons Public Domain Dedication waiver (http://creativecommons.org/publicdomain/zero/1.0/) applies to the data made available in this article, unless otherwise stated. 
that functional outcome after RSA for acute PHF in such a cohort are superior to HA [7, 9, 13]. However, the impact of TH on function after RSA has only received limited study. Furthermore, it is unclear if certain design features of a given RSA like the humeral inclination angle affect the clinical outcome and GT healing rate.

The aim of this study was to evaluate functional outcome and influence of TH following RSA with $135^{\circ}$ humeral inclination and a standard glenosphere without lateralization or inferiorization for PHFs. The hypothesis was that $\mathrm{TH}$ would lead to improvement in functional outcome.

\section{Materials and methods}

A single center retrospective case series of all PHFs treated with RSA during a four-year period was performed. Institutional review board approval was obtained. All patients signed informed consent and gave their approval for the use of clinical and radiographic data for scientific purposes.

Inclusion criteria:

- Surgical treatment between January 1, 2012 and December 31, 2016

- An acute PHF defined as treatment within 6 weeks of injury

- Minimum clinical and radiographic follow-up of 24 months

\section{Exclusion criteria:}

- Previous surgery of the involved shoulder

- Patients with severe neurological disorders unable to follow the postoperative management regime

- Revision shoulder arthroplasty

\section{Surgical technique}

Preoperative X-rays in 2 planes (anterior-posterior (AP) and $\mathrm{Y}$-view) and a computed tomography (CT) scan were obtained. All patients underwent surgery in beach chair position under general or regional anesthesia. Surgery was performed by one single surgeon (LL). A deltopectoral approach was performed in all cases using a consistent implant system (Univers Revers; Arthrex, Naples, USA). The humeral stem was cemented in 19 cases (50\%) and placed in a press-fit fashion in 19 cases (50\%) depending on the bone quality. In this cohort in all cases a humeral inclination angle of $135^{\circ}$ was selected. Tenotomy of the long head of the biceps was routinely performed. Following identification of the tuberosities and resection of the humeral head, a baseplate was placed on the glenoid. In all cases a standard glenosphere without lateralization or inferiorization was selected. The glenosphere size was chosen depending on the patient's anatomy: $36 \mathrm{~mm}$ in 10 cases, $39 \mathrm{~mm}$ in 26 cases and $42 \mathrm{~mm}$ in 2 cases. Following fixation of the humeral stem, the tuberosities were horizontally sutured around the stem of the prosthesis with a double suture cerclage (Fibertape, Arthrex). An additional vertical suture was applied between humeral shaft and prosthesis in a figure-of-eight configuration in all cases. The cerclage technique is illustrated in Fig. 1.

Postoperatively the shoulder was immobilized in an abduction pillow for 6 weeks. Passive range of motion was initiated after 3 weeks. The sling was removed after 6 weeks and active range of motion was allowed. Strengthening began 12 weeks postoperatively.

\section{Postoperative Evaluation.}

The patients were asked to grade pain on a visual analogue scale (VAS). Active range of motion (ROM) was measured with a goniometer for elevation, abduction, and external rotation of the elbow at the side. Internal rotation was judged by the level of vertebra reached by the thumb and was graded with a numeric ordinal scale. Functional outcome was assessed using the Constant score (CS) as shoulder specific score. In addition, the Subjective Shoulder Value (SSV) was used as patient-focused outcome tool.

Radiographic assessment at follow-up was performed by one examiner (JS) based on an AP view in neutral rotation and an axial view. Greater and lesser TH was assessed as yes or no. When it was in an anatomical position on the axial view and visible on the AP X-ray the GT was considered to be healed. The LT was evaluated on the axial view. Scapular notching was evaluated in the AP view according to Sirveaux [14].

\section{Statistical analysis}

Statistical analysis was performed with SPSS version 22 (IBM, Armonk, USA) using the independent samples Mann-Whitney U-test and the Kruskal-Wallis test. Quantitative variables were described by means, standard deviations, minimums and maximums. Normal distributions were tested by the Shapiro-Wilk test and confirmed graphically by histogram. In order to determine prognostic factors for the functional outcome correlation between ROM, VAS, SSV, CS and the following parameters were tested: $\mathrm{TH}$, fixation technique of the stem (cemented vs. press fit) and age. $P$ values $\leq 0.05$ were considered to be significant.

\section{Results}

58 patients met the inclusion criteria. $13(20 \%)$ were deceased from unrelated causes and 7 (11\%) were lost to follow-up leaving 38 patients available for follow-up at a mean of $34 \pm 5$ months after surgery. The mean age was 77 [62-97] years at the time of surgery. All fractures were classified according to the Neer [15] and the OTA 


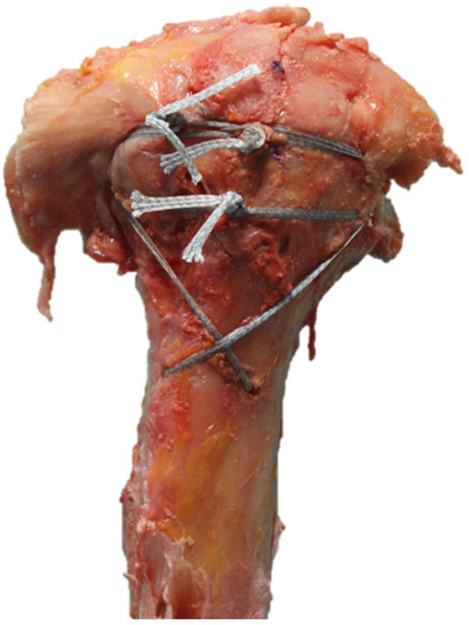

b

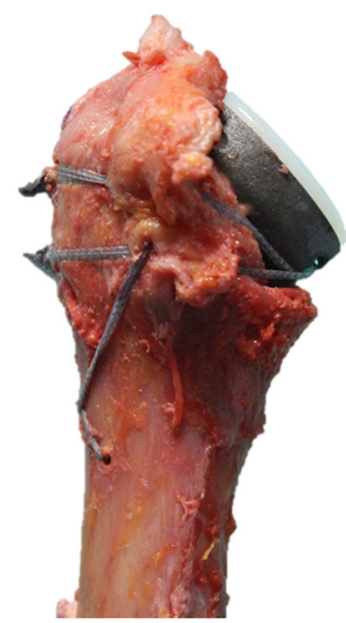

Fig. 1 Technique of tuberosity repair. The tuberosity fragments are reconstructed horizontally around the neck of the prosthesis with two suture cerclages. These go through a hole at the medial neck of the prosthesis and the subscapularis and infraspinatus tendons. In the vertical plane, a cerclage in a figure-of-8 technique reduces the tuberosities to the shaft $\mathbf{a}, \mathbf{b}$

[16] classification. Baseline characteristics are summarized in Table 1.

Mean postoperative abduction was $111^{\circ} \pm 20^{\circ}$, mean forward flexion was $132^{\circ} \pm 22^{\circ}$ and mean external rotation at the side was $25^{\circ} \pm 13^{\circ}$. Mean internal rotation was at vertebra L5. The mean CS was 61 [24-80] points, the

Table 1 Baseline characteristics. SD standard deviation

\begin{tabular}{ll}
\hline Variable & \\
\hline$n$ & 38 \\
Mean patient age in years [SD] & $77[ \pm 8]$ \\
Mean follow-up in months [SD] & $34[ \pm 5]$ \\
Gender & \\
Men & $5(13 \%)$ \\
Women & $33(87 \%)$ \\
Injured side & \\
Right & $26(68 \%)$ \\
Left & $12(32 \%)$ \\
Neer Classification & \\
Type I (1-part) & 0 \\
Type II (2-part) & 0 \\
Type III (3-part) & $5(13 \%)$ \\
Type IV (4-part) & $33(87 \%)$ \\
Humeral fixation & \\
Press fit & $19(50 \%)$ \\
Cemented & $19(50 \%)$ \\
OTA/AO Classification & \\
B2 & 5 \\
C2 & 31 \\
C3 & 2 \\
\hline
\end{tabular}

mean age-adapted CS was 74 [30-99] percent and the mean SSV was 74 [20-100] percent. Average pain level on the VAS was $1 \pm 1$ out of 10 points. Patient outcomes are outlined in Table 2.

The overall healing rate of the GT was $82 \%$. GT healing significantly improved CS (65 vs. 41 points; $p<$ 0.001 ), patient satisfaction (SSV $79 \%$ vs. $48 \%$; $p<0.001$ ), abduction $\left(117^{\circ}\right.$ vs. $\left.81^{\circ} ; P<0.001\right)$, forward flexion $\left(139^{\circ}\right.$ vs. $\left.99^{\circ} ; \mathrm{p}<0.001\right)$ and external rotation $\left(28^{\circ}\right.$ vs. $10^{\circ} ; p=$

Table 2 Postoperative outcome. SD standard deviation; L5 lumbar vertebra 5

Outcome paramete

Mean Constant score [range] 61 [24-80]

Mean adjusted Constant score [range] 74 [30-99]

Mean Subjective Shoulder Value score [range] $\quad 74$ [20-100]

Mean pain level on Visual Analogue Scale [SD] $1[ \pm 1]$

Mean abduction [range]

$111^{\circ}\left[ \pm 20^{\circ}\right]$

Mean forward flexion [range]

$132^{\circ}\left[ \pm 22^{\circ}\right]$

Mean external rotation at $0^{\circ}$ [range]

$25^{\circ}\left[ \pm 13^{\circ}\right]$

Mean internal rotation $\quad$ L5

Complications

$2(5 \%)$

Revision surgery

$2(5 \%)$

Implant failure

0

Greater tuberosity healed

$31(82 \%)$

Lesser tuberosity healed

$33(87 \%)$

Inferior notching according to Sirveaux $\quad 8 \%$

- grade 1

- grade 2

- grade $3 \quad 0$

- grade 4 
Table 3 Outcome according to greater tuberosity healing. ADL activities of daily living; GT greater tuberosity; L4 lumbar vertebra 4; $n$ number; n.S. not significant; $S 1$ sacral vertebra 1; SD standard deviation

\begin{tabular}{llll}
\hline Variable & GT healed & GT not healed & $p$-value \\
\hline$n$ & 31 & 7 & \\
Age at surgery in years [SD] & $77 \pm 10$ & $76 \pm 11$ & n.s. \\
Constant Score in points [SD] & $65 \pm 7$ & $41 \pm 11$ & $<0.001$ \\
Pain [SD] & $14 \pm 2$ & $10 \pm 5$ & 0.001 \\
ADL [SD] & $17 \pm 3$ & $12 \pm 3$ & $<0.001$ \\
Mobility [SD] & $29 \pm 4$ & $16 \pm 5$ & $<0.001$ \\
Strength [SD] & $6 \pm 3$ & $2 \pm 2$ & 0.003 \\
Subjective Shoulder Value [SD] & $79 \% \pm 11$ & $48 \pm 20$ & $<0.001$ \\
Active abduction & $117^{\circ} \pm 23^{\circ}$ & $81^{\circ} \pm 15^{\circ}$ & $<0.001$ \\
Active forward flexion & $139^{\circ} \pm 21^{\circ}$ & $99^{\circ} \pm 28^{\circ}$ & $<0.001$ \\
Active external rotation & $28^{\circ} \pm 15^{\circ}$ & $10^{\circ} \pm 10^{\circ}$ & 0.002 \\
Active internal rotation & $\mathrm{L4}$ & $\mathrm{S} 1$ & n.S.
\end{tabular}

0.002). The difference in functional results between patients with anatomic GT healing and those in whom it was resorbed are summarized in Table 3. Interestingly, all patients except one (86\%) who presented GT resorption were females.

Two exemplary cases with and without GT healing are illustrated in Fig. 2 and Fig. 3.

Overall LT healing was $87 \%$, however, it did not affect internal rotation or functional outcome.

Regarding humeral fixation technique (cemented vs. press-fit) no statistical differences could be observed.

Patient age did not negatively correlate with the outcome.

Inferior notching occurred in 3 cases (8\%), of which all 3 were grade 1 .

The complication and revision rate was 5\%. One case presented with a postoperative hematoma which had to be surgically addressed. Another patient suffered an atraumatic dislocation which was treated with revision surgery and a metaphyseal extension of $6 \mathrm{~mm}$ was additionally
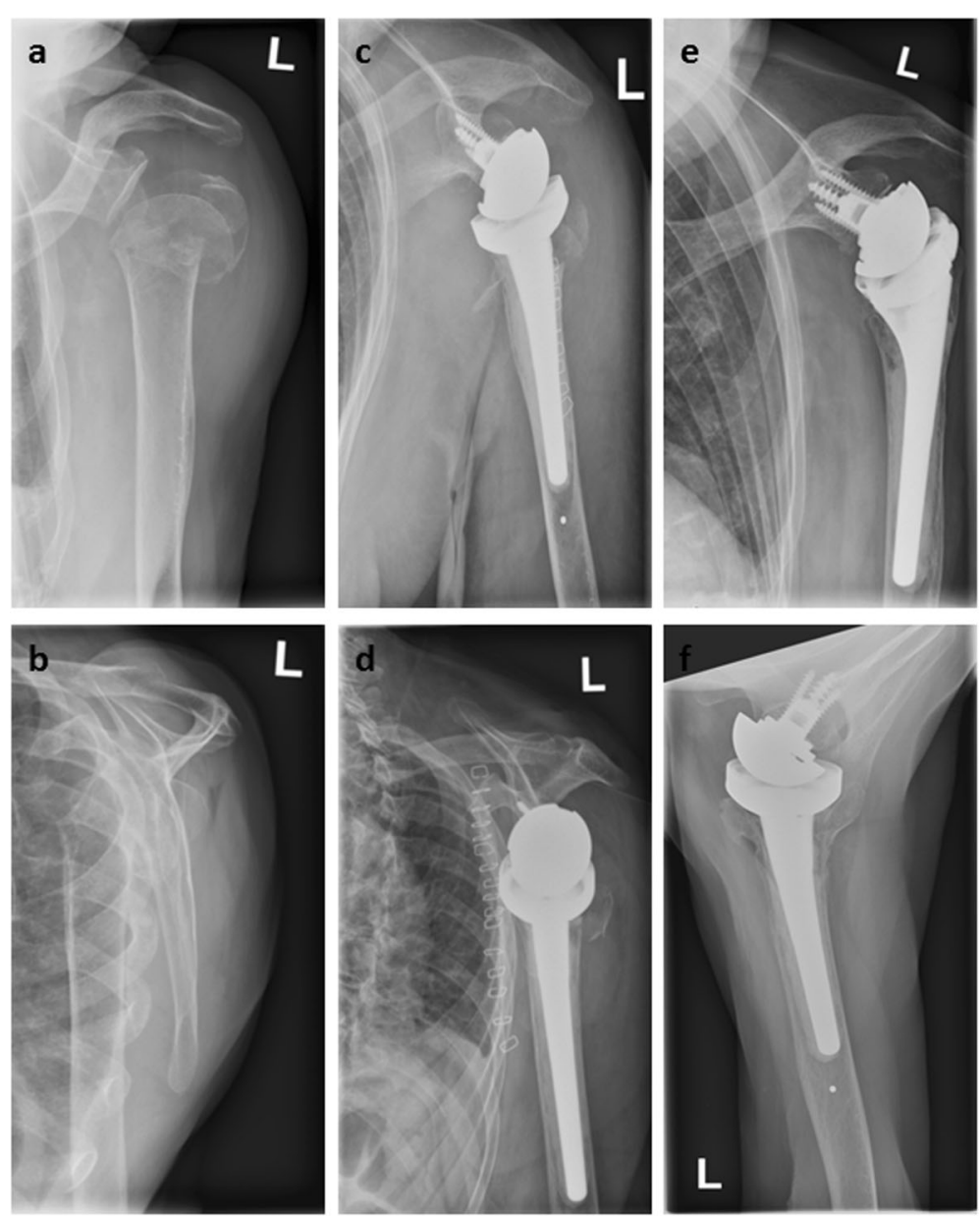

Fig. 2 Pre- a, b, postoperative $\mathbf{c}, \mathbf{d}$ and follow-up images $\mathbf{e}, \mathbf{f}$ of a 97-year-old patient with a 11-C2-fracture of the proximal humerus who was treated with primary reverse shoulder arthroplasty. At final follow-up after 24 months the Constant Score was 68 points. Both lesser and greater tuberosity are healed in an anatomical position $\mathbf{e}, \mathbf{f}$ 

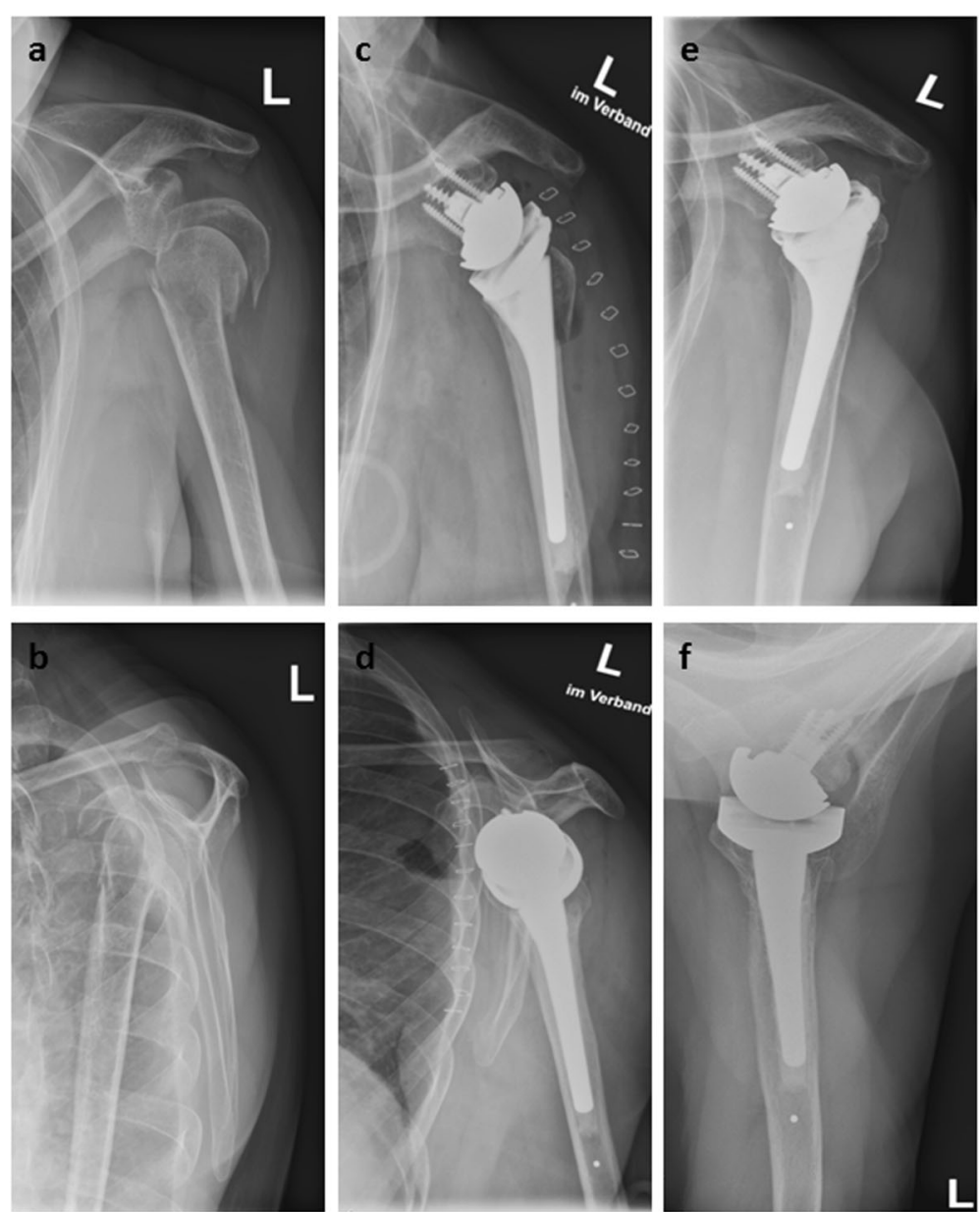

Fig. 3 Pre- a, b, postoperative $\mathbf{c}, \mathbf{d}$ and follow-up images $\mathbf{e}$, $\mathbf{f}$ of a 68-year-old patient with a 11-C2-fracture of the proximal humerus who was treated with primary reverse shoulder arthroplasty. At final follow-up after 36 months the Constant Score was 51 points. The lesser tuberosity healed in an anatomic position; however, the greater tuberosity was resorbed $\mathbf{f}$

implanted; no further dislocation occurred. No prosthesis required removal during the study period.

\section{Discussion}

Multiple studies unanimously showed good clinical short- to midterm results and a low complication and revision rate after RSA for acute PHF in the elderly [7, 9, $13,17-21]$.

It is well established that bony healing of the tuberosities in an anatomical position is the most important single factor for a good clinical outcome after primary implantation of a HA for fracture [4, 10, 22]. Resorption or dislocation of the tuberosities leads to dysfunction of the rotator cuff and significant functional limitations $[8$, $10,15]$.

In contrast to the results from HA, the need and potential benefits of tuberosity refixation in case of RSA remain controversial as the deltoid muscle can partially compensate for the loss of internal and external rotation, caused by rotator cuff deficiency or tuberosity resorption, through medialization and caudalization of the fulcrum. To date, $\mathrm{TH}$ rates between 37 and $84 \%$ have been reported in the literature in RSA for acute PHF in the elderly population $[7,9,13,17-21]$. .

Several recent studies have examined the influence of GT healing on functional outcome after RSA for acute PHF, therefore, we compared our results with the available literature as shown in Table 4.

(Table 4 should appear here in production of the manuscript)

The results of this study confirm our hypothesis that functional outcome is improved following RSA for PHF when GT healing occurs. TH was associated with superior functional outcome and higher patient satisfaction compared to when the tuberosity did not heal.

In contrast to our findings, Torrens et al. [20] reported a cohort of 41 patients with PHF treated with a primary $155^{\circ}$ RSA at an average of 29 months. The GT healing rate was $68 \%$ but $\mathrm{TH}$ did not affect the CS. Chun et al. [21] examined a cohort of 38 patients who underwent 
Table 4 Comparison of studies evaluating outcome and influence of tuberosity healing after reverse shoulder arthroplasty in proximal humeral fractures in elderly. ASES American shoulder and elbow surgeons score; CS constant score; GT greater tuberosity; No. number; n.r. not reported

\begin{tabular}{|c|c|c|c|c|c|c|c|c|c|}
\hline Study (year) & $\begin{array}{l}\text { No. of } \\
\text { patients }\end{array}$ & $\begin{array}{l}\text { Mean follow } \\
\text { up (months) }\end{array}$ & Implant type & $\begin{array}{l}\text { GT } \\
\text { healing } \\
\text { rate }\end{array}$ & $\begin{array}{l}\text { Overall } \\
\text { outcome }\end{array}$ & $\begin{array}{l}\text { Outcome } \\
\text { GT healed }\end{array}$ & $\begin{array}{l}\text { Outcome GT } \\
\text { not healed }\end{array}$ & $\begin{array}{l}\text { Scapular } \\
\text { notching }\end{array}$ & $\begin{array}{l}\text { Complication } \\
\text { rate }\end{array}$ \\
\hline Cuff (2013) (6) & 24 & 30 & $135^{\circ}$ (DJO Altivate) & $83 \%$ & $\begin{array}{l}77 \text { pts. } \\
\text { (ASES) }\end{array}$ & $\begin{array}{l}78 \text { pts. } \\
\text { (ASES) }\end{array}$ & 75 pts. (ASES) & $0 \%$ & $8 \%$ \\
\hline $\begin{array}{l}\text { Gallinet (2013) } \\
\text { [8] }\end{array}$ & 41 & 24 & $\begin{array}{l}155^{\circ} \text { (DePuy Delta } 3 \\
{[24]} \\
\text { Tornier Aequalis [20] } \\
\text { Zimmer Anatomical } \\
\text { Reverse [9]) }\end{array}$ & $66 \%$ & n.r. & 60 pts. (CS) & 52 pts. (CS) & $73 \%$ & $10 \%$ \\
\hline $\begin{array}{l}\text { Sebastiá Forcada } \\
\text { (2014) [12] }\end{array}$ & 31 & 29 & $155^{\circ}$ (Lima SMR) & $65 \%$ & $\begin{array}{l}56 \text { pts. } \\
\text { (CS) }\end{array}$ & 59 pts. (CS) & 54 pts. (CS) & $3 \%$ & $6 \%$ \\
\hline $\begin{array}{l}\text { Garofalo (2015) } \\
\text { [16] }\end{array}$ & 87 & 27 & $\begin{array}{l}155^{\circ} \text { (Tornier } \\
\text { Aequalis Fracture) }\end{array}$ & $75 \%$ & n.r. & n.r. & n.r. & $1 \%$ & $5 \%$ \\
\hline $\begin{array}{l}\text { Grubhofer (2016) } \\
\text { [17] }\end{array}$ & 51 & 35 & $\begin{array}{l}155^{\circ} \text { (Zimmer } \\
\text { Anatomical Reverse) }\end{array}$ & $84 \%$ & $\begin{array}{l}62 \mathrm{pts} . \\
(\mathrm{CS})\end{array}$ & 65 pts. (CS) & 50 pts. (CS) & $63 \%$ & $8 \%$ \\
\hline Chun (2017) [20] & 38 & 37 & $\begin{array}{l}155^{\circ} \text { (Tornier } \\
\text { Aequalis) }\end{array}$ & $37 \%$ & n.r. & 68 pts. (CS) & 64 pts. (CS) & $29 \%$ & $0 \%$ \\
\hline $\begin{array}{l}\text { Torrens (2018) } \\
\text { [19] }\end{array}$ & 41 & 29 & $\begin{array}{l}155^{\circ} \text { (Depuy Delta } \\
\text { Xtend) }\end{array}$ & $68 \%$ & $\begin{array}{l}61 \mathrm{pts} . \\
(\mathrm{CS})\end{array}$ & 61 pts. (CS) & 61 pts. (CS) & $15 \%$ & $2 \%$ \\
\hline $\begin{array}{l}\text { Boileau (2019) } \\
{[18]}\end{array}$ & 37 & 36 & $\begin{array}{l}155^{\circ} \text { (Tornier } \\
\text { Aequalis Fracture) }\end{array}$ & $84 \%$ & $\begin{array}{l}64 \text { pts. } \\
\text { (CS) }\end{array}$ & 64 pts. (CS) & 51 pts. (CS) & $47 \%$ & $5 \%$ \\
\hline Current study & 38 & 34 & $\begin{array}{l}135^{\circ} \text { (Arthrex } \\
\text { Univers Reverse) }\end{array}$ & $82 \%$ & $\begin{array}{l}61 \text { pts. } \\
\text { (CS) }\end{array}$ & 65 pts. (CS) & 41 pts. (CS) & $8 \%$ & $5 \%$ \\
\hline
\end{tabular}

RSA with $155^{\circ}$ for PHF. GT healing rate was only $37 \%$ and there were no statistical differences in the overall functional outcome regardless of TH. Nevertheless, external rotation was significantly better in the healed GT group $\left(29^{\circ}\right.$ vs. $\left.10^{\circ}\right)$. In a randomized controlled trial comparing $\mathrm{HA}$ and RSA with $155^{\circ}$ for PHF Sebastiá-Forcada et al. [13] reported that in the RSA group with 31 patients functional outcome was also irrespective of $\mathrm{TH}$.

On the contrary, Gallinet et al. [23] compared patients treated with different $155^{\circ}$ prosthesis with and without tuberosity repair. In this study, the patients with tuberosity fixation exhibited better CS and the patients with successful $\mathrm{TH}$ yielded better shoulder function. In addition, both Grubhofer et al. [18] and Boileau et al. [19] reported significantly better functional outcome and patient satisfaction in case of $155^{\circ}$ RSA with successful $\mathrm{TH}$.

Consistent with these findings, we believe our results demonstrate that $\mathrm{TH}$ should be an important goal after RSA for PHF. In particular, because successful TH after RSA not only improves functional outcome but also may contribute to the avoidance of complications. In case of failed GT healing or tuberosity resection, high rates of complications (up to 40\%) have been reported in some RSA case series for PHF [24-28]. In a series of 30 acute fractures treated with RSA without tuberosity reattachment, Cazeneuve et al. [26] reported 2 cases of instability, 2 with implant loosening, 1 with infection, and 7 with proximal humeral bone lysis. Klein et al. [29] described 2 early infections and 2 dislocations in a case series of 20 PHF treated with RSA and excision of the tuberosities. Gallinet et al. [9] analyzed 24 patients without or with failed tuberosity repair and observed 2 infections and 1 anterior dislocation of the implant. We did observe one atraumatic dislocation in our series, interestingly, this also occurred in a patient with failed tuberosity repair. In our opinion the reattachment of the tuberosities and the adjacent rotator cuff tendons stabilizes the implanted prosthesis and guarantees better soft tissue coverage which minimizes the risk of infection. Nevertheless, there is a variety of other factors that may be attributed to the mentioned complications like surgical technique, patient associated factors (e.g. age, gender or osteopenia) and implant design.

As shown in Table 4, the GT healing rate is highly varying. These differences may be attributed to fixation techniques and the type of prosthesis used. Recent efforts to enhance TH after RSA in complex fractures include modifications in implant design like fracture specific humeral stems with large ingrowth surface $[17,19]$ as well as bone graft techniques [27]. Considering the literature, the highest GT healing rates (around 80\%) were either achieved with a $135^{\circ}$ prosthesis or with a $155^{\circ}$ prosthesis with a specific fracture stem.

Cuff et al. [7] performed a prospective cohort study comparing $\mathrm{HA}$ with RSA for PHF in patients $>70$ years. 
In this study, the DJO Reverse Shoulder Prosthesis (DJO Surgical, Austin, USA) with a humeral inclination of $135^{\circ}$ was used. However, compared to the $135^{\circ}$ prosthesis used in our study, the DJO RSA implicates more glenoid lateralization. The GT healing rate was $83 \%$ and is similar to the $82 \%$ we achieved. Similar GT healing rates with a $155^{\circ}$ prosthesis were only reported by Grubhofer et al. [18] in a cohort of 51 patients using the Zimmer Reverse System (Zimmer Biomet, Warsaw, USA) with a fracture specific stem and Garofalo et al. [17] as well as Boileau et al. [19] with a combination of autologous bone grafting and a fracture specific stem (that incorporates a cancellous bone autograft). We suspect that RSA with a humeral inclination of $135^{\circ}$ allows refixation of the tuberosities in a more anatomic position and therefore might result in decreased stress on the tuberosity repair compared to a $155^{\circ}$ prosthesis, thus successful GT repair in RSA is more predictable without having to use a fracture specific stem. However, it is clear that there are several other factors that may affect tuberosity healing like e.g. the fixation technique (number and kind of sutures/cables) or the bone quality.

Another advantage of the $135^{\circ}$ design is the reduced risk for scapular notching. In 2015, a systematic review taking into account 38 studies and 2222 shoulders was published comparing RSA with $135^{\circ}$ and $155^{\circ}$ humeral inclination: it was reported that $135^{\circ}$ inclination resulted in significantly less scapular notching without a higher rate of complications or significant differences in functional results relative to $155^{\circ}$ inclination [30]. Whereas Erickson et al. [30] compared RSA with $155^{\circ}$ and $135^{\circ}$ implants and a lateralized glenosphere (Altivate; DJO Surgical), we used a different RSA with $135^{\circ}$ inclination (Univers Revers; Arthrex) without lateralized glenosphere. In our eyes, in PHF without preexisting cuff tear arthropathy or osteoarthritis, the joint line is not medialized, therefore, all prostheses were implanted without lateralization of the glenosphere. Lateralization of the glenosphere is an established measure to reduce scapular notching; however, even without lateralization, we observed a very low rate of scapular notching. These findings are consistent with those reported by Cuff. et al. who also used a $135^{\circ}$ prosthesis. In contrast, scapular notching rates up to $73 \%$ [23] are reported for the $155^{\circ}$ prosthesis (see Table 4). This also correlates with the experimental results of $\mathrm{Oh}$ et al. [31] who found that a $135^{\circ}$ prosthesis does not impinge until an average of $12^{\circ}$ degrees of adduction, whereas a $155^{\circ}$ prosthesis will notch with the arm resting at the side. The impact of scapular notching on the clinical outcome remains controversial $[14,32,33]$ but there is consensus that it should be avoided because of possible complications in the long term [34].

There are several limitations to the current study. First, our study has the inherent limitations of a retrospective series. Second, we did not compare the outcomes of $155^{\circ}$ or $135^{\circ}$ humeral inclinations as the surgeon in this study preferred the latter. While we believe our results support the use of a $135^{\circ}$ prosthesis based on the high $\mathrm{TH}$ rate and the low occurrence of scapular notching, a randomized controlled trial may be needed to confirm these findings. Third, the follow-up is short- to midterm and could change over time.

\section{Conclusion}

RSA with $135^{\circ}$ humeral inclination and a neutral glenosphere for PHF leads to good functional outcome in combination with a high rate of $\mathrm{TH}$ and a low rate of scapular notching. The short-term revision rate is low and the results are predictable and continuous. TH is associated with improved ROM and functional outcome.

\section{Abbreviations \\ AP: Anterior-posterior; CS: Constant score; GT: Greater tuberosity; HA: Hemiarthroplasty; LT: Lesser tuberosity; PHF: Proximal humeral fracture; RSA: Reverse shoulder arthroplasty; SSV: Subjective shoulder value; $\mathrm{TH}$ : Tuberosity healing}

\section{Acknowledgements}

None.

Author disclosures

Dr. Lehmann and Dr. Gerhardt are consultants for Arthrex, Inc.

\section{Authors' contributions}

MJ, NS and JS examined the patients. JS analyzed the data and wrote the manuscript. CG and LL designed the study and substantively revised the written article. All authors have read and approved the final manuscript.

\section{Funding}

None.

\section{Availability of data and materials}

The datasets used and/or analysed during the current study are available from the corresponding author on reasonable request.

Ethics approval and consent to participate

The study was approved by the local Ethics committee of the University of Mannheim/Heidelberg, Germany. Written informed consent was obtained from all patients. Ethics approval number 2018-826R-MA.

Consent for publication

Not applicable.

\section{Competing interests}

The authors declare that they have no competing interests.

\section{Author details}

${ }^{1}$ Department of Traumatology and Hand Surgery, St. Vincentius Clinic, Karlsruhe, Academic Teaching Hospital Albert-Ludwigs-University Freiburg, Suedendstraße 32, D-76137 Karlsruhe, Germany. ${ }^{2}$ Medical Faculty Mannheim, Karls-Ruprecht-University Heidelberg, Mannheim, Germany.

Received: 8 October 2019 Accepted: 10 January 2020

Published online: 16 January 2020

\section{References}

1. Murray IR, Amin AK, White TO, Robinson CM. Proximal humeral fractures: current concepts in classification, treatment and outcomes. J Bone Jt Surg Br Vol. 2011;93-B(1):1-11. 
2. Schliemann B, Heilmann LF, Raschke MJ, Lill H, Katthagen JC, Ellwein A. Isolated fractures of the greater tuberosity: when are they treated conservatively?: a baseline study. Obere Extrem. 2018;13(2):106-11.

3. Bastian JD, Hertel R. Osteosynthesis and hemiarthroplasty of fractures of the proximal humerus: outcomes in a consecutive case series. J Shoulder Elb Surg. 2009;18(2):216-9.

4. Krause FG, Huebschle L, Hertel R. Reattachment of the tuberosities with cable wires and bone graft in hemiarthroplasties done for proximal humeral fractures with cable wire and bone graft: 58 patients with a 22-month minimum follow-up. J Orthop Trauma. 2007:21(10):682-6.

5. Reineck JR, Krishnan SG, Burkhead WZ. Four-part proximal Humerus fractures: evaluation and treatment. Hand Clin. 2007;23(4):415-24.

6. Kettler M, Biberthaler P, Braunstein V, Zeiler C, Kroetz M, Mutschler W. Treatment of proximal humeral fractures with the PHILOS angular stable plate. Presentation of 225 cases of dislocated fractures. Unfallchirurg. 2006; 109(12):1032-40

7. Cuff DJ, Pupello DR. Comparison of Hemiarthroplasty and reverse shoulder Arthroplasty for the treatment of proximal humeral fractures in elderly patients. J Bone Jt Surg. 2013;95(22):2050-5.

8. Greiner SH, Diederichs G, Kröning I, Scheibel M, Perka C. Tuberosity position correlates with fatty infiltration of the rotator cuff after hemiarthroplasty for proximal humeral fractures. J Shoulder Elb Surg. 2009;18(3):431-6.

9. Gallinet $D$, Clappaz $P$, Garbuio $P$, Tropet $Y$, Obert L. Three or four parts complex proximal humerus fractures: Hemiarthroplasty versus reverse prosthesis: a comparative study of 40 cases. Orthop Traumatol Surg Res. 2009;95(1):48-55.

10. Boileau P, Krishnan SG, Tinsi L, Walch G, Coste JS, Mole D. Tuberosity malposition and migration: reasons for poor outcomes after hemiarthroplasty for displaced fractures of the proximal humerus. J Shoulder Elb Surg. 2002;11(5):401-12.

11. Levy JC, Badman B. Reverse shoulder prosthesis for acute four-part fracture: tuberosity fixation using a horseshoe graft. J Orthop Trauma. 2011 May; 25(5):318-24.

12. Grammont PM, Baulot E. Delta shoulder prosthesis for rotator cuff rupture. Orthop. 1993 Jan;16(1):65-8.

13. Sebastiá-Forcada E, Cebrián-Gómez R, Lizaur-Utrilla A, Gil-Guillén V. Reverse shoulder arthroplasty versus hemiarthroplasty for acute proximal humeral fractures. A blinded, randomized, controlled, prospective study. J Shoulder Elb Surg. 2014;23(10):1419-26.

14. Lévigne C, Boileau P, Favard L, Garaud P, Molé D, Sirveaux F, et al. Scapular notching in reverse shoulder arthroplasty. J Shoulder Elb Surg. 2008;17(6): 925-35.

15. Neer CS 2nd. Indications for replacement of the proximal humeral articulation. Am J Surg. 1955 Apr;89(4):901-7.

16. Meinberg EG, Agel J, Roberts CS, Karam MD, Kellam JF. Fracture and dislocation classification Compendium-2018. J Orthop Trauma. 2018 Jan; 32(Suppl 1):S1-170.

17. Garofalo R, Flanagin B, Castagna A, Lo EY, Krishnan SG. Reverse shoulder arthroplasty for proximal humerus fracture using a dedicated stem: radiological outcomes at a minimum 2 years of follow-up-case series. J Orthop Surg Res. 2015;10(1):1-8.

18. Grubhofer F, Wieser K, Meyer DC, Catanzaro S, Beeler S, Riede U, et al. Reverse total shoulder arthroplasty for acute head-splitting, 3- and 4-part fractures of the proximal humerus in the elderly. J Shoulder Elb Surg. 2016; 25(10):1690-8.

19. Boileau P, Alta TD, Decroocq L, Sirveaux F, Clavert P, Favard L, et al. Reverse shoulder arthroplasty for acute fractures in the elderly: is it worth reattaching the tuberosities? J Shoulder Elb Surg. 2018;28(3):437-44.

20. Torrens C, Alentorn-Geli E, Mingo F, Gamba C, Santana F. Reverse shoulder arthroplasty for the treatment of acute complex proximal humeral fractures: influence of greater tuberosity healing on the functional outcomes. J Orthop Surg. 2018;26(1):230949901876013.

21. Chun YM, Kim DS, Lee DH, Shin SJ. Reverse shoulder arthroplasty for fourpart proximal humerus fracture in elderly patients: can a healed tuberosity improve the functional outcomes? J Shoulder Elb Surg. 2017;26(7):1216-21.

22. Demirhan M, Kilicoglu O, Altinel L, Eralp L, Akalin Y. Prognostic factors in prosthetic replacement for acute proximal humerus fractures. J Orthop Trauma. 2003 Mar;17(3):181-9.

23. Gallinet D, Adam A, Gasse N, Rochet S, Obert L. Improvement in shoulder rotation in complex shoulder fractures treated by reverse shoulder arthroplasty. J Shoulder Elb Surg. 2013;22(1):38-44.
24. Bufquin T, Hersan A, Hubert L, Massin P. Reverse shoulder arthroplasty for the treatment of three- and four-part fractures of the proximal humerus in the elderly. J Bone Joint Surg Br. 2007;89-B(4):516-20.

25. Cazeneuve J-F, Cristofari DJ. Delta III reverse shoulder arthroplasty: radiological outcome for acute complex fractures of the proximal humerus in elderly patients. Orthop Traumatol Surg Res. 2009;95(5):325-9.

26. Cazeneuve JF, Cristofari D-J. The reverse shoulder prosthesis in the treatment of fractures of the proximal humerus in the elderly. J Bone Joint Surg Br. 2010;92-B(4):535-9.

27. Formaini NT, Everding NG, Levy JC, Rosas S. Tuberosity healing after reverse shoulder arthroplasty for acute proximal humerus fractures: the "black and tan" technique. J Shoulder Elb Surg. 2015;24(11):e299-306.

28. Lenarz C, Shishani Y, McCrum C, Nowinski RJ, Edwards TB, Gobezie R. Is reverse shoulder Arthroplasty appropriate for the treatment of fractures in the older patient?: early observations. Clin Orthop Relat Res. 2011;469(12): 3324-31.

29. Klein M, Juschka M, Hinkenjann B, Scherger B, Ostermann PAW. Treatment of comminuted fractures of the proximal humerus in elderly patients with the Delta III reverse shoulder prosthesis. J Orthop Trauma. 2008;22(10):698-704.

30. Erickson BJ, Frank RM, Harris JD, Mall N, Romeo AA. The influence of humeral head inclination in reverse total shoulder arthroplasty: a systematic review. J Shoulder Elb Surg. 2015;24(6):988-93.

31. Oh JH, Shin SJ, McGarry MH, Scott JH, Heckmann N, Lee TQ. Biomechanical effects of humeral neck-shaft angle and subscapularis integrity in reverse total shoulder arthroplasty. J Shoulder Elb Surg. 2014;23(8):1091-8.

32. Mata-Fink A, Meinke M, Jones C, Kim B, Bell J-E. Reverse shoulder arthroplasty for treatment of proximal humeral fractures in older adults: a systematic review. J Shoulder Elb Surg. 2013;22(12):1737-48.

33. Torrens C, Santana F, Picazo B, Caceres E. Retrospective study of scapular notches in reverse shoulder arthroplasties. Am J Orthop (Belle Mead NJ). 2013 Aug;42(8):362-5.

34. Groh Gl, Groh GM. Complications rates, reoperation rates, and the learning curve in reverse shoulder arthroplasty. J Shoulder Elb Surg. 2014;23(3):388-94.

\section{Publisher's Note}

Springer Nature remains neutral with regard to jurisdictional claims in published maps and institutional affiliations.

\section{Ready to submit your research? Choose BMC and benefit from:}

- fast, convenient online submission

- thorough peer review by experienced researchers in your field

- rapid publication on acceptance

- support for research data, including large and complex data types

- gold Open Access which fosters wider collaboration and increased citations

- maximum visibility for your research: over $100 \mathrm{M}$ website views per year

At $\mathrm{BMC}$, research is always in progress.

Learn more biomedcentral.com/submissions 